\title{
Prediction models for the risk of gestational diabetes: a systematic review
}

\author{
Marije Lamain - de Ruiter ${ }^{1 *}$, Anneke Kwee ${ }^{1}$, Christiana A. Naaktgeboren², Arie Franx ${ }^{1}$, Karel G. M. Moons ${ }^{2}$ \\ and Maria P. H. Koster ${ }^{1,3}$
}

\begin{abstract}
Background: Numerous prediction models for gestational diabetes mellitus (GDM) have been developed, but their methodological quality is unknown. The objective is to systematically review all studies describing first-trimester prediction models for GDM and to assess their methodological quality.

Methods: MEDLINE and EMBASE were searched until December 2014. Key words for GDM, first trimester of pregnancy, and prediction modeling studies were combined. Prediction models for GDM performed up to 14 weeks of gestation that only include routinely measured predictors were eligible.

Data was extracted by the CHecklist for critical Appraisal and data extraction for systematic Reviews of prediction Modelling Studies (CHARMS). Data on risk predictors and performance measures were also extracted. Each study was scored for risk of bias.

Results: Our search yielded 7761 articles, of which 17 were eligible for review (14 development studies and 3 external validation studies). The definition and prevalence of GDM varied widely across studies. Maternal age and body mass index were the most common predictors. Discrimination was acceptable for all studies. Calibration was reported for four studies. Risk of bias for participant selection, predictor assessment, and outcome assessment was low in general. Moderate to high risk of bias was seen for the number of events, attrition, and analysis.

Conclusions: Most studies showed moderate to low methodological quality, and few prediction models for GDM have been externally validated. External validation is recommended to enhance generalizability and assess their true value in clinical practice.
\end{abstract}

Keywords: First trimester, Gestational diabetes, Model, Prediction, Quality assessment, Systematic review, Validation

\section{Background}

Gestational diabetes mellitus (GDM), diabetes diagnosed by oral glucose tolerance test (OGTT) in the second or third trimester that is not clearly overt diabetes [1], is becoming the number one complication in pregnancy. Over the past decade, the prevalence of GDM has rapidly risen and ranges from 3 up to $35 \%[2,3]$ depending on the definitions used and populations studied $[4,5]$. This parallels the emerging trends in obesity, population aging, and diabetes mellitus type II. The rising prevalence of GDM contributes to an increasing number of adverse perinatal outcomes, such as macrosomia,

\footnotetext{
* Correspondence: m.deruiter-7@umcutrecht.nl

'Birth Centre, Division Woman and Baby, University Medical Centre Utrecht, KE.04.123.1, PO BOX 850903508 AB Utrecht, The Netherlands

Full list of author information is available at the end of the article
}

shoulder dystocia, caesarean delivery, and neonatal hypoglycemia [6]. Moreover, GDM has a major impact on long-term maternal health as well as neonatal health. The mother is at high risk to develop diabetes mellitus type II within 5 years after pregnancy [7-9], and her child is at increased risk of developing childhood obesity and metabolic syndrome [10-12]. Early diagnosis of GDM will allow for timely treatment, such as dietary counseling or pharmacotherapy, which has been shown to be effective for the improvement of perinatal outcomes [13-15].

Early risk stratification by prediction modeling might offer opportunities to improve care for those women at high risk of developing GDM. As timely intervention is the key to preventing (or reducing) adverse outcomes in GDM, clinicians need prediction models that can be 
used in the first trimester. Additionally, as all pregnancies should be assessed for the risk of developing GDM, models that only require easily obtained information are preferable. Although various prediction models for GDM have been developed, they are not widely used in routine clinical practice. Ideally, new prediction models are externally validated and updated before they are implemented. A systematic review describing the characteristics of the model development, the included predictors, outcome measurement, and whether they have undergone external validation will provide insight into the current quality of first-trimester GDM prediction models. This will improve validation and implementation of prediction models for GDM. For this purpose, we generated a comprehensive overview of all published first-trimester prediction models for GDM consisting of routinely measured predictors and assessed the methodological quality of these studies.

\section{Methods}

The specifics of our research question, which was framed according to the CHecklist for critical Appraisal and data extraction for systematic Reviews of prediction Modelling Studies (CHARMS) guidance [16], are shown in Table 1 . The results have been reported conforming to the PRISMA statement [see Additional file 1].

\section{Search strategy}

We performed a computerized systematic search in MEDLINE and EMBASE on December 17, 2014. Key words for GDM and first trimester of pregnancy were combined with a validated search strategy for prediction modeling studies [17]. Detailed information on the exact search syntax is presented in Additional file 2. Reference lists of the selected articles were scanned to ascertain that no relevant articles were missed.

\section{Study selection}

In this systematic review, we aimed to identify all published prognostic prediction models that are applicable in the first trimester of pregnancy (up to 14 weeks of gestational age). Moreover, we focused on reviewing the prediction models including routinely measured predictors only (i.e., predictors based on maternal characteristics, anthropometric measures, or glucose measurement) to enhance the generalizability of our review.

Model development studies as well as validation studies were eligible. Eligibility assessment of studies was independently performed by two authors (MLdR, MPHK) by screening the title and abstract. Exclusion criteria for selection were preconception prediction, univariate prediction studies, diagnostic models, prediction models including invasive measures (e.g., biomarkers, ultrasound measures), association studies of one or more variables and the outcome, no primary reports (e.g., systematic reviews), conference abstracts, and other languages than English, French, or German. Next, full-text articles were thoroughly reviewed by two authors (MLdR, MPHK). Any disagreement between reviewers was resolved by consensus. Authors of the original studies were contacted by e-mail for further information if necessary.

\section{Assessment of methodological quality}

For critical appraisal of the individual studies, we used the recently published CHARMS checklist [16]. In summary, the following items of the CHARMS checklist were handled: study characteristics and participants; outcome to be predicted; candidate predictors (for development studies only); sample size and handling of missing data; model development (for development studies only); model evaluation; and results and interpretation.

One reviewer (MLdR) extracted data according to the CHARMS checklist from the included studies. A second author (MPHK) checked the extracted data. Disagreements were resolved by consensus between these two authors. After data extraction, each study was scored for risk of bias as follows: "low" if bias was unlikely; "moderate" if there were no essential shortcomings, but not all criteria were satisfied; and "high" if bias was very likely due to essential errors in one or more of the domains [18].

\section{Data extraction}

For each included study, the method of GDM diagnostic strategy and criteria were obtained in detail. Moreover, risk predictors that were included in the prediction

Table 1 Framework of the research question

\begin{tabular}{ll}
\hline Item & Description \\
\hline Intended scope of the review & $\begin{array}{l}\text { Reviewing prognostic models that are aimed at predicting the development of gestational } \\
\text { diabetes in pregnancy } \\
\text { Bype of prediction modeling studies }\end{array}$ \\
$\begin{array}{l}\text { Target population to whom the prediction } \\
\text { model applies }\end{array}$ & $\begin{array}{l}\text { Low- and medium-risk pregnant women in the first trimester of pregnancy } \\
\text { Outcome to be predicted }\end{array}$ \\
$\begin{array}{l}\text { Intended moment of using the model } \\
\text { Probability of developing gestational diabetes in current pregnancy }\end{array}$
\end{tabular}


model as well as indicators of performance measures were extracted. The actual predictive performance was also extracted and reported as the area under the (receiver operating) curve (AUC or $c$-statistic) or as classifications measures, such as sensitivity, specificity, positive predictive value, and negative predictive value.

\section{Results}

\section{Study selection}

An overview of the flow of the systematic review process is given in Fig. 1. Our computerized search yielded a total of 7761 unique articles. Of these, 7621 articles were excluded on the basis of the title and abstract and another 123 articles on the basis of full-text screening. Reference cross-checking of the selected papers yielded no additional studies. Thus, a total of 17 studies on firsttrimester prediction modeling for GDM were identified for inclusion in this review [19-34]. Fourteen studies were development studies and another three studies were external validation studies. All studies were published between 1997 and 2014 and conducted in 11 different countries: three in the UK, two in Italy, two in the Netherlands, two in Greece, two in Canada, and one in Australia, Iran, Russia, Turkey, the USA, or Vietnam.

\section{Outcome assessment}

All extracted data on diagnostic strategies for GDM are shown in Additional file 3. Eight different diagnostic outcome (i.e., GDM) criteria were used in the included studies. The prevalence of GDM within the included studies ranged from 2.4\% (model 14) to 26.5\% (model 7). The diagnostic criteria differed in the dose of oral glucose to be administered, number of glucose levels measured, time interval of glucose measures, and cutoff point of glucose levels. The oldest criteria used, by Carpenter and Coustan and the National Diabetes Data

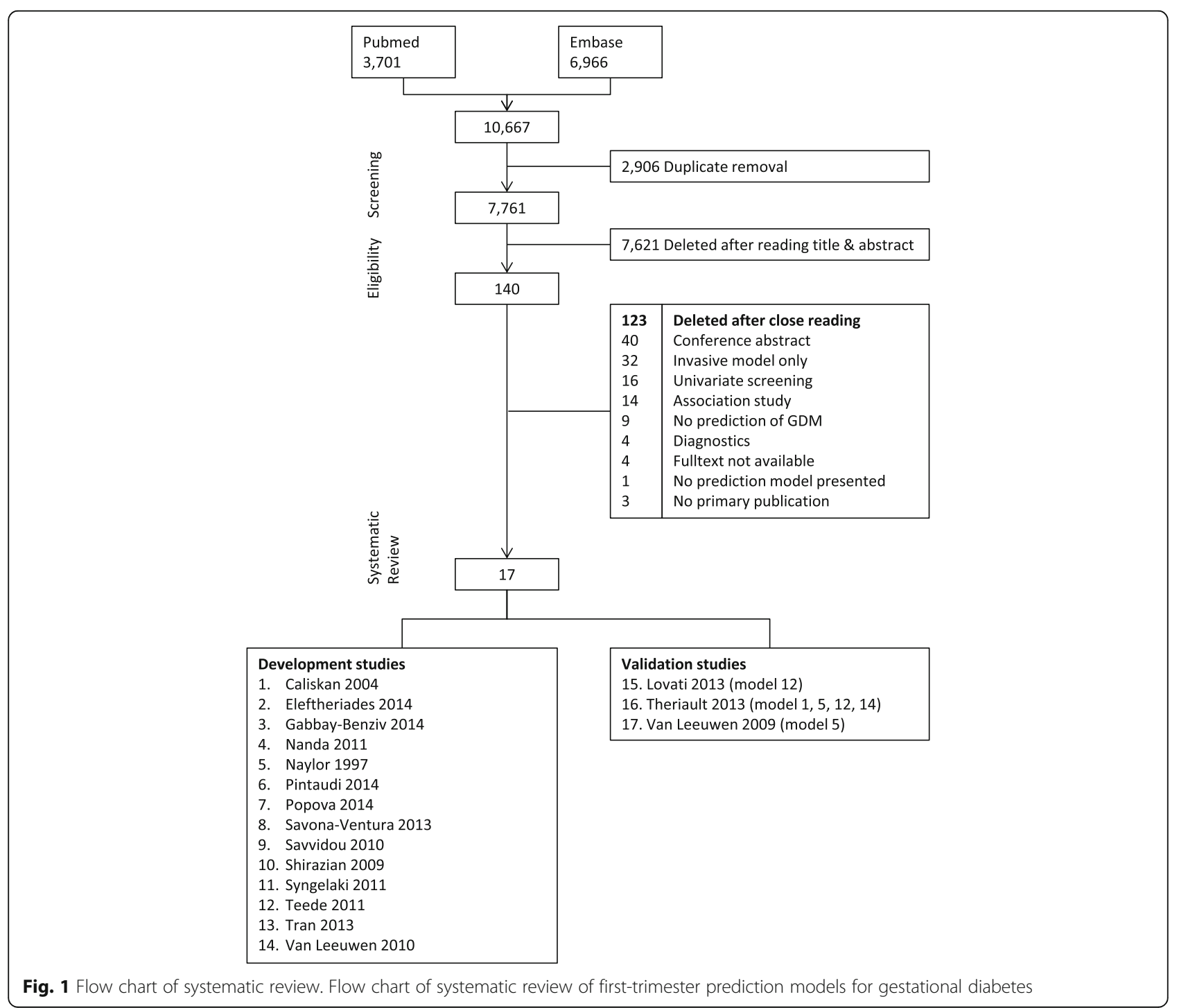


Group, were the only criteria that prescribed a $100-\mathrm{g}$ dose of glucose and a four-point blood glucose level measurement. All other, more recent, GDM criteria used a 75-g dose of glucose.

The included studies had different strategies for setting the diagnosis of GDM: six studies used a one-step approach by applying an OGTT to all participants for diagnosing GDM (models 2, 6, 8, 10, 13, and 15). In another five studies, a two-step approach was performed using a $50-\mathrm{g}$ glucose challenge test followed by an OGTT (models 1, 3, 5, 12, and 16). Five studies used another two-step approach, in which a screening method (i.e., random glucose, risk factor, or a combination of screening) was followed by an OGTT (models 4, 9, 11, 14, and 17). The remaining study did not clearly report their strategy, but they did report on their diagnostic criteria (model 7).

\section{Risk of bias assessment}

Table 2 shows the risk of bias for each included study based on six predefined domains, and Fig. 2 provides a summarized overview of potential bias. For participant selection, predictor assessment, and outcome assessment, the majority of the studies were scored as low risk of bias $(n=13-15 ; 76-88 \%)$. None of the studies had a high risk of bias in these categories. A moderate risk of bias for participant selection was mainly due to debatable inclusion or exclusion criteria. Predictor assessment was at moderate risk for three models because assessment of predictors was performed in retrospect, after

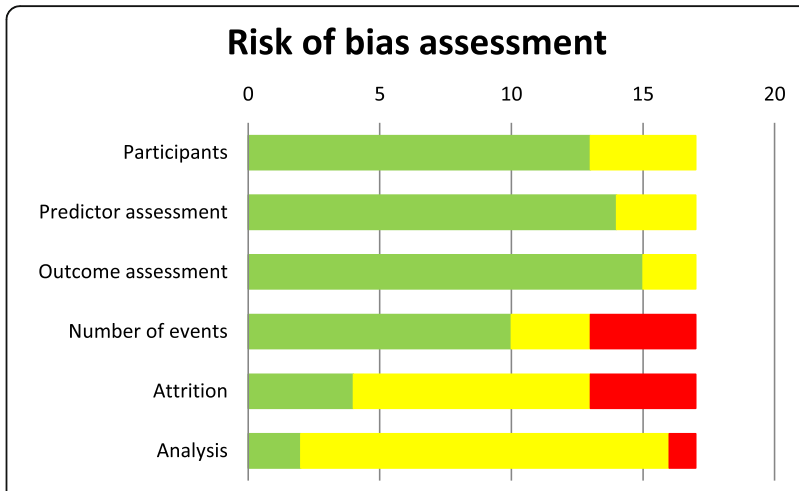

Fig. 2 Risk of bias assessment summary. Risk of bias assessment for six predefined domains for each included study. Legend: green, low risk of bias; yellow, medium risk of bias; red, high risk of bias

the outcome (GDM) was known. Two studies had a moderate risk of bias regarding outcome assessment due to different reasons: (1) two different diagnostic criteria for GDM were used in the study period (model 15) and (2) diagnosis of GDM based on risk factor screening only, which is a less sensitive approach (model 9) [35].

The number of events was scored as high risk of bias for four models (24\%) because they had less than six events per variable (EPV) or because we were unable to extract the EPV. A moderate risk was scored for three (18\%) other prediction models with an EPV between six and ten or with a very low number of cases $(<50)$ for external validation.

Table 2 Risk of bias assessment

\begin{tabular}{|c|c|c|c|c|c|c|}
\hline Study & Participants & Predictor & Outcome & No. of events & Attrition & Analysis \\
\hline 1. Caliskan 2004 & $L$ & L & L & L & M & $\mathrm{H}$ \\
\hline 2. Eleftheriades 2014 & M & L & L & M & L & M \\
\hline 3. Gabbay-Benziv 2014 & $L$ & L & L & $\mathrm{H}$ & M & M \\
\hline 4. Nanda 2011 & $L$ & L & L & $L$ & $\mathrm{H}$ & M \\
\hline 5. Naylor 1997 & $L$ & L & L & M & M & M \\
\hline 6. Pintaudi 2014 & $L$ & M & L & L & M & M \\
\hline 7. Popova 2014 & $L$ & M & L & L & $\mathrm{H}$ & M \\
\hline 8. Savona-Ventura 2013 & M & M & L & L & M & M \\
\hline 9. Savvidou 2010 & $L$ & L & M & L & $\mathrm{H}$ & M \\
\hline 10. Shirazian 2009 & $L$ & L & L & $\mathrm{H}$ & M & M \\
\hline 11. Syngelaki 2011 & $L$ & L & L & $\mathrm{H}$ & M & M \\
\hline 12. Teede 2011 & $L$ & L & L & L & $\mathrm{H}$ & M \\
\hline 13. Tran 2013 & $L$ & L & L & L & M & M \\
\hline 14. Van Leeuwen 2010 & M & L & L & $\mathrm{H}$ & L & L \\
\hline 15. Lovati 2013 & M & L & M & L & L & M \\
\hline 16. Theriault 2014 & $L$ & L & L & L & M & M \\
\hline 17. Van Leeuwen 2009 & $\mathrm{~L}$ & L & L & M & L & L \\
\hline
\end{tabular}


Assessment of attrition (i.e., no loss to follow-up) showed a high risk of bias for four (24\%) of the prediction models. These four studies were scored as high risk due to lack of information on sample flow or on missing data. Most studies $(n=9,53 \%)$ performed a complete case analysis; these models were scored as moderate risk of bias.

Information on development of the prediction models was insufficiently reported in almost all studies $(n=14$; $82 \%$ ), and therefore, all scored a moderate risk. Only two studies (from the same research group) reported a complete description of the analysis performed (models
14 and 17). A high risk of bias was present in one study where no information on model development was provided (model 1).

\section{Predictors in the final model}

An overview of the predictors in the final models in each study is shown in Table 3. The smallest final prediction model consisted of two predictors and the largest of eight predictors. Age and body mass index were the most common predictors; both were included in 11 prediction models. Four models included other anthropometric measures, i.e., maternal weight, blood pressure,

Table 3 Calibration and discrimination of development studies

\begin{tabular}{|c|c|c|c|c|c|c|c|c|}
\hline \multirow[t]{2}{*}{ Study } & \multicolumn{2}{|l|}{ Risk predictors } & \multicolumn{3}{|l|}{ AUC } & \multirow[t]{2}{*}{ Calibration } & \multirow[t]{2}{*}{ Sensitivity } & \multirow[t]{2}{*}{ Specificity } \\
\hline & Predictors and no. of predictor & & $\begin{array}{l}\text { Original } \\
\text { study }\end{array}$ & $\begin{array}{l}\text { External } \\
\text { validation } 1\end{array}$ & $\begin{array}{l}\text { External } \\
\text { validation } 2\end{array}$ & & & \\
\hline 1. Caliskan 2004 & $\begin{array}{l}\text { Poor outcome, age, BMl, } \\
\text { fam hx of DM, hx of } \\
\text { macrosomia }\end{array}$ & 5 & NR & $\begin{array}{l}0.68 \\
{[0.65-0.71]}\end{array}$ & & & $\begin{array}{l}85.7 \\
{[67.4-100]}\end{array}$ & $\begin{array}{l}67 \\
{[59.4-74.8]}\end{array}$ \\
\hline 2. Eleftheriades 2014 & Weight, age & 2 & $\begin{array}{l}0.73 \\
{[0.65-0.81]}\end{array}$ & & & & $\begin{array}{l}32.4 \\
\text { NR }\end{array}$ & $\begin{array}{l}90 \\
N R\end{array}$ \\
\hline 3. Gabbay-Benziv 2014 & $\begin{array}{l}\text { Age, ethnicity, hx of GDM, } \\
\text { hx of macrosomia }\end{array}$ & 5 & $\begin{array}{l}0.81 \\
{[0.77-0.87]}\end{array}$ & & & $p=0.18$ & $\begin{array}{l}85 \\
{[74.6-93.2]}\end{array}$ & $\begin{array}{l}62 \\
{[57.4-64.0]}\end{array}$ \\
\hline 4. Nanda 2011 & $\begin{array}{l}\text { Age, BMl, ethnicity, hx of } \\
\text { GDM, hx of macrosomia }\end{array}$ & 5 & $\begin{array}{l}0.79 \\
{[0.76-0.82]}\end{array}$ & & & & $\begin{array}{l}52.9 \\
\text { NR }\end{array}$ & $\begin{array}{l}90 \\
N R\end{array}$ \\
\hline 5. Naylor 1997 & Age, BMl, ethnicity & 3 & $\begin{array}{l}0.69 \\
\text { NR }\end{array}$ & $\begin{array}{l}0.67 \\
{[0.64-0.70]}\end{array}$ & $\begin{array}{l}0.64 \\
{[0.56-0.72]}\end{array}$ & $p=0.93$ & $\begin{array}{l}65.9 \\
\text { NR }\end{array}$ & $\begin{array}{l}84 \\
N R\end{array}$ \\
\hline 6. Pintaudi 2014 & $\begin{array}{l}\text { BMl, glucose, hx of } \\
\text { macrosomia, } \\
\text { fam hx of DM }\end{array}$ & 4 & NR & & & & $\begin{array}{l}89 \\
N R\end{array}$ & $\begin{array}{l}40 \\
N R\end{array}$ \\
\hline 7. Popova 2014 & BMl, glucose, AC, PCOS & 4 & NR & & & & $N R$ & NR \\
\hline 8. Savona-Ventura 2013 & Age, glucose, blood pressure & 3 & $\begin{array}{l}0.89 \\
{[0.86-0.91]}\end{array}$ & & & & $\begin{array}{l}96.6 \\
N R\end{array}$ & $\begin{array}{l}37.5 \\
\text { NR }\end{array}$ \\
\hline 9. Savvidou 2010 & $\begin{array}{l}\text { Age, BMI, ethnicity, hx of } \\
\text { GDM, mode of conception, } \\
\text { parity, smoking }\end{array}$ & 7 & $\begin{array}{l}0.82 \\
N R\end{array}$ & & & & $N R$ & $N R$ \\
\hline 10. Shirazian 2009 & Age, BMl, fam hx of DM & 3 & NR & & & & $N R$ & NR \\
\hline 11. Syngelaki 2011 & $\begin{array}{l}\text { Age, BMl, ethnicity, mode of } \\
\text { conception, smoking, hx of } \\
\text { chronic hypertension, } \\
\text { parity, hx of macrosomia }\end{array}$ & 8 & NR & & & & $N R$ & $N R$ \\
\hline 12. Teede 2011 & $\begin{array}{l}\text { Age, BMl, ethnicity, fam } \\
\text { hx of DM, hx of GDM }\end{array}$ & 5 & $\begin{array}{l}0.70 \\
\text { NR }\end{array}$ & $\begin{array}{l}0.74 \\
{[0.70-0.78]}\end{array}$ & $\begin{array}{l}0.60 \\
{[0.56-0.64]}\end{array}$ & & $\begin{array}{l}68.0 \\
{[61.3-73.9]}\end{array}$ & $\begin{array}{l}70.8 \\
{[68.8-72.6]}\end{array}$ \\
\hline $\begin{array}{l}\text { 13. Tran } 2013 \\
\text { ADA criteria }\end{array}$ & Age, BMl & 2 & $\begin{array}{l}0.71 \\
{[0.68-0.75]}\end{array}$ & & & & $\begin{array}{l}79.9 \\
\text { NR }\end{array}$ & $\begin{array}{l}48.5 \\
\text { NR }\end{array}$ \\
\hline $\begin{array}{l}\text { 13. Tran } 2013 \\
\text { IADPSG criteria }\end{array}$ & Age, BMl, fam hx of DM & 3 & $\begin{array}{l}0.65 \\
{[0.62-0.67]}\end{array}$ & & & & $\begin{array}{l}70.4 \\
\text { NR }\end{array}$ & $\begin{array}{l}52.5 \\
\text { NR }\end{array}$ \\
\hline $\begin{array}{l}\text { 13. Tran } 2013 \\
\text { WHO criteria }\end{array}$ & Age, BMl & 2 & $\begin{array}{l}0.63 \\
{[0.60-0.65]}\end{array}$ & & & & $\begin{array}{l}65.1 \\
\text { NR }\end{array}$ & $\begin{array}{l}53.7 \\
\text { NR }\end{array}$ \\
\hline $\begin{array}{l}\text { 13. Tran } 2013 \\
\text { ADIPS criteria }\end{array}$ & Age, BMl & 2 & $\begin{array}{l}0.64 \\
{[0.62-0.67]}\end{array}$ & & & & $\begin{array}{l}64.1 \\
\text { NR }\end{array}$ & $\begin{array}{l}56.8 \\
\text { NR }\end{array}$ \\
\hline 14. Van Leeuwen 2010 & $\begin{array}{l}\text { BMl, ethnicity, fam hx } \\
\text { of DM, hx of GDM }\end{array}$ & 5 & $\begin{array}{l}0.77 \\
{[0.69-0.85]}\end{array}$ & $\begin{array}{l}0.76 \\
{[0.73-0.79]}\end{array}$ & & $p=0.25$ & $\begin{array}{l}45.8 \\
{[28.2-64.5]}\end{array}$ & $\begin{array}{l}88.4 \\
{[87.9-88.8]}\end{array}$ \\
\hline
\end{tabular}

Abbreviations: $A C$ abdominal circumference, $A U C$ area under the (receiver operating) curve, $B M I$ body mass index, DM diabetes mellitus, fam family, GDM gestational diabetes, $h x$ history, NR not reported, PCOS polycystic ovary syndrome 
and abdominal circumference. Risk factors based on obstetric history were often included; five models included a history of GDM and four a history of macrosomia. Five models included a positive family history of diabetes. Routine obstetric care often includes a blood glucose level measurement at the beginning of pregnancy to rule out pre-existing diabetes. Three models included this glucose level measurement.

\section{Predictive performance}

Table 3 summarizes the predictive performance of the prediction models. The $c$-statistic of nine of the development studies that reported predictive performance ranged from 0.63 to 0.89 . The three external validation studies showed $c$-statistics from 0.60 to 0.76 . Median sensitivity and specificity were 67 and $71 \%$ and 66 and $65 \%$ for development and validation studies, respectively.

Although external validation is necessary to assess the true value of prediction models, the majority of developed models $(71 \%)$ has not yet been externally validated. Two models (models 5 and 12) used an internal validation technique, and four of the developed models were externally validated (models 1, 5, 12, and 14). Their external performance measures were slightly lower compared to the original results.

Calibration was reported for four studies (24\%; models $3,5,14$, and 17), by means of a Hosmer-Lemeshow test, a $\chi^{2}$ goodness of fit, or a calibration plot. The external validation of model 5 showed a poor goodness of fit $(p=0.06)$; the other three models showed adequate calibration.

\section{Discussion}

\section{Main findings}

In this systematic review on first-trimester prediction models for GDM, consisting of routine measures only, we identified 14 development studies and three external validation studies based on four of the developed models. Assessment of methodological quality revealed various shortcomings on the model development studies, resulting in a moderate to low quality of the reviewed models.

These shortcomings all lead to overfitted prediction models. Overfitting means that a prediction model is too closely tailored to the data at hand, which makes it less likely for a model to perform well in practice, in the same or in a different population. The likeliness of overfitting is high, as most authors did not report on the number of candidate predictors they considered or on the predictor selection technique used (e.g., dichotomization of variables, univariable significance criteria for inclusion). Additionally, handling of missing data can also be a source of bias. Only two studies handled missing data according to the most preferable standards, i.e., by multiple imputation [36]. At last, as a crucial step prior to implementation, validation of developed prediction models in external datasets (i.e., datasets that were not used to develop the model) is needed. All development studies described in this review have a high risk of bias, which often show overestimated performance measures. We found that only four out of the 14 identified models have been externally validated, despite knowing that external validation in independent data is all that matters. The models showing the highest $c$-statistic in our review have not yet been externally validated (i.e., models 3, 8, and 9).

\section{Strengths and limitations}

To our knowledge, this is the first systematic review on prediction models for GDM. As the number of prediction models for GDM is rapidly increasing, it is important to generate an overview of the quality and characteristics of models that are already available. A major strength of our review is that it is based on a validated search strategy for prediction models. Furthermore, all prediction models were thoroughly assessed on quality by means of the CHARMS guideline.

However, some limitations need to be addressed. We restricted our inclusion criteria to models consisting of routine measures only. Therefore, promising prediction models that also use more invasive measurements may have been missed. Leaving aside that studies on the added value of biomarkers to noninvasive models are scarce, the biomarkers that have been studied for the prediction of GDM show that their predictive performance is limited and contradictory results have been published [32, 37-39]. For future studies, we recommend to assess the added value of biomarkers only for prediction models that have been proven to perform well in external validation studies.

A second limitation of our systematic review might be the highly variable measures of outcome, which hampers the comparison of prediction models for GDM. GDM was diagnosed by eight different criteria and by even more diagnostic strategies, reflecting the variation in currently used international diagnostic criteria [40, 41]. Though sub-analysis according to the criteria used would be interesting, we expect subgroups to be so small that this will severely limit the value of sub-analysis. Moreover, it is known that the differentiation in diagnostic strategies and criteria has a major impact on the prevalence of GDM [31, 41]. There is an international guideline for diagnostic strategies and criteria for GDM [42], but international implementation is hampered by the ongoing debate on a "gold standard." For a fair comparison of prediction models for GDM, universally implemented diagnostic strategy and criteria of GDM would be of great benefit. 


\section{Interpretation}

Our systematic review identified multiple prediction models for GDM in the first trimester of pregnancy consisting of routine measures only, most of them showing moderate to low methodological quality. Correspondingly, other systematic reviews on prognostic models in different fields (i.e., cancer prognosis, low back pain prognosis, and prognosis of pregnancy complications) also report the frequent occurrence of inadequate methods for development of prediction models [43-45]. The recently published guidelines that advocate for transparent reporting of prediction models may function as a tool to improve reporting on methodological quality, also in obstetric research [46].

Although most studies showed promising predictive performance in development studies, this systematic review shows there is an urgent need of external validation of the most promising ones. A recently published external validation study did not validate the models with the best performance measures [47]. The lack of external validation of these results leads to limited generalizability, as development data often leads to inaccurate predictions when applied to other individuals than the individuals in the original study [16]. Therefore, we strongly advocate an external validation and head-to-head comparison of all models that were identified in this systematic review.

Assuming that performances reported in development studies may be confirmed in external validation studies, prediction models for GDM show a performance at least as good as traditional risk factor screening, as recommended by current guidelines [48, 49]. However, prediction model-based GDM screening might offer the opportunity to reduce the burden of diagnosing GDM (e.g., only applying an OGTT to women at high risk of developing GDM). Current guidelines for GDM diagnostic strategies show a high sensitivity (>90\%), but a very low specificity (3-35\%), therefore requiring the administration of an OGTT to the majority of the population (up to 97\%) [4]. Hopefully, when prediction models will be implemented into routine obstetric care, fewer women undergo an OGTT while still maintaining the high sensitivity. Therefore, a prediction model based on routine measures will probably also be a cost-effective intervention. There will also be opportunities for prevention of GDM as models can be applied as early as the first trimester of pregnancy. Knowledge on the efficacy of prevention of GDM is not yet conclusive as several trials are still ongoing [50]. Preventive strategies and targeted care would be in line with a greater trend in health care towards a more personalized approach of health care delivery: "the right treatment for the right person at the right time" [51].

\section{Conclusions}

Although many first-trimester prediction models for GDM have been developed, only few have been externally validated and most showed moderate to low methodological quality. Before implementation of prediction models in clinical practice can take place, it is important that their true value is assessed by external validation in the population in which they are to be used. As the best and most promising prediction models have not yet been externally validated, we recommend an external validation and head-to-head comparison of these models before including them in clinical guidelines and daily practice. Hopefully, this will guide implementation of prediction models for GDM into clinical practice and provide room for targeted interventions in pregnancy.

\section{Additional files}

Additional file 1: PRISMA 2009 Checklist. The file contains the PRISMA checklist and indicates were data is described in the manuscript. (DOCX 29 kb)

Additional file 2: Search string. The file contains the full search string used for our computerized search of prediction models for gestational diabetes mellitus. (DOCX $14 \mathrm{~kb}$ )

Additional file 3: CHARMS checklist for each included study (full version). The file contains all data extracted from the studies included in our systematic review conforming to the CHARMS checklist. (DOCX $47 \mathrm{~kb}$ )

\begin{abstract}
Abbreviations
AUC: Area under the (receiver operating) curve; CHARMS: CHecklist for critical Appraisal and data extraction for systematic Reviews of prediction Modelling Studies; EPV: Events per variable; GDM: Gestational diabetes mellitus; OGTT: Oral glucose tolerance test
\end{abstract}

\section{Acknowledgements}

The authors would like to thank Rebecca Louhanepessy for assisting in the screening of titles and abstracts.

\section{Funding}

This work was supported by The Netherlands Organization for Health Research and Development (project nr 209020004).

\section{Availability of data and materials}

All data generated or analyzed during this study are included in this published article and its supplementary information files.

\section{Authors' contributions}

All authors had the original idea for the study. MLdR, RL, and MPHK were involved in article selection and data extraction. MLdR analyzed the data and interpreted the data together with MPHK. MLdR, CAN, AK, and MPHK wrote the first draft of the manuscript, which was revised by AF and KGMM. All authors approved the final version of the manuscript. MPHK and AF are the guarantors of this study.

\section{Competing interests}

The authors declare that they have no competing interests.

Consent for publication

Not applicable.

Ethics approval and consent to participate Not applicable. 


\section{Author details}

${ }^{1}$ Birth Centre, Division Woman and Baby, University Medical Centre Utrecht, KE.04.123.1, PO BOX 850903508 AB Utrecht, The Netherlands. ${ }^{2} J u l i u s$ Centre for Health Sciences and Primary Care, University Medical Centre Utrecht, Str. 6.131, PO BOX 855003508 AB Utrecht, The Netherlands. ${ }^{3}$ Department of Obstetrics and Gynaecology, Erasmus MC, University Medical Centre, PO Box 20403000 CA Rotterdam, The Netherlands.

Received: 10 August 2016 Accepted: 28 October 2016

Published online: 08 February 2017

\section{References}

1. American Diabetes Association. Classification and diagnosis of diabetes. Diabetes Care. 2016;39:S13-22.

2. DeSisto CL, Kim SY, Sharma AJ. Prevalence estimates of gestational diabetes mellitus in the United States, Pregnancy Risk Assessment Monitoring System (PRAMS), 2007-2010. Prev Chronic Dis. 2014;11:130415.

3. Lavery JA, Friedman AM, Keyes KM, Wright JD, Ananth CV. Gestational diabetes in the United States: temporal changes in prevalence rates between 1979 and 2010. BJOG. 2016;1-10. http://onlinelibrary.wiley.com/ doi/10.1111/1471-0528.14236/full.

4. Teh WT, Teede HJ, Paul E, Harrison CL, Wallace EM, Allan C. Risk factors for gestational diabetes mellitus: implications for the application of screening guidelines. Aust New Zeal J Obstet Gynaecol. 2011;51:26-30.

5. Yuen $\mathrm{L}$, Wong WW. Gestational diabetes mellitus: challenges for different ethnic groups. World J Diabetes. 2015;6:1024-32.

6. Metzger BE, Lowe LP, Dyer AR, Trimble ER, Chaovarindr U, Coustan DR, et al. Hyperglycemia and adverse pregnancy outcomes. N Engl J Med. 2008;358: 1991-2002.

7. O'Sullivan JB. Diabetes mellitus after GDM. Diabetes. 1991;40(suppl):131-5.

8. Bellamy L, Casas J-P, Hingorani AD, Williams D. Type 2 diabetes mellitus after gestational diabetes: a systematic review and meta-analysis. Lancet. 2009:373:1773-9.

9. $X u$ Y, Shen S, Sun L, Yang H, Jin B, Cao X. Metabolic syndrome risk after gestational diabetes: a systematic review and meta-analysis. PLoS One. 2014; 9, e87863.

10. Boney CM, Verma A, Tucker R, Vohr BR. Metabolic syndrome in childhood: association with birth weight, maternal obesity, and gestational diabetes mellitus. Pediatrics. 2005;115:e290-6.

11. Hillier TA, Pedula KL, Schmidt MM, Mullen JA, Charles M-A, Pettitt DJ. Childhood obesity and metabolic imprinting: the ongoing effects of maternal hyperglycemia. Diabetes Care. 2007;30:2287-92.

12. Clausen TD, Mathiesen ER, Hansen T, Pedersen $O$, Jensen DM, Lauenborg J, et al. High prevalence of type 2 diabetes and pre-diabetes in adult offspring of women with gestational diabetes mellitus or type 1 diabetes: the role of intrauterine hyperglycemia. Diabetes Care. 2008;31:340-6.

13. Alwan N, Tuffnell DJ, West J. Treatments for gestational diabetes. Cochrane Database Syst Rev. 2009;8, CD003395.

14. Landon MB, Spong CY, Thom E, Carpenter MW, Ramin SM, Casey B, et al. A multicenter, randomized trial of treatment for mild gestational diabetes. $\mathrm{N}$ Engl J Med. 2009;361:1339-48.

15. Viana LV, Gross JL, Azevedo MJ. Dietary intervention in patients with gestational diabetes mellitus: a systematic review and meta-analysis of randomized clinical trials on maternal and newborn outcomes. Diabetes Care. 2014;37:3345-55.

16. Moons KGM, de Groot JAH, Bouwmeester W, Vergouwe Y, Mallett S, Altman $D G$, et al. Critical appraisal and data extraction for systematic reviews of prediction modelling studies: the CHARMS checklist. PLoS Med. 2014;11, e1001744.

17. Geersing GJ, Bouwmeester W, Zuithoff P, Spijker R, Leeflang M, Moons KGM. Search filters for finding prognostic and diagnostic prediction studies in Medline to enhance systematic reviews. PLoS One. 2012;7:3-8.

18. Smit HA, Pinart M, Antó JM, Keil T, Bousquet J, Carlsen KH, et al. Childhood asthma prediction models: a systematic review. Lancet Respir Med. 2015;3: 973-84

19. Caliskan E, Kayikcioglu F, Ozturk N, Koc S, Haberal A. A population-based risk factor scoring will decrease unnecessary testing for the diagnosis of gestational diabetes mellitus. Acta Obstet Gynecol Scand. 2004;83:524-30.

20. Eleftheriades M, Papastefanou I, Lambrinoudaki I, Kappou D, Lavranos D, Akalestos A, et al. Elevated placental growth factor concentrations at 11-14 weeks of gestation to predict gestational diabetes mellitus. Metabolism. 2014:63:1419-25.

21. Gabbay-Benziv R, Doyle LE, Blitzer M, Baschat AA. First trimester prediction of maternal glycemic status. J Perinat Med. 2014;43:283-9.

22. Nanda S, Savvidou M, Syngelaki A, Akolekar R, Nicolaides KH. Prediction of gestational diabetes mellitus by maternal factors and biomarkers at 11 to 13 weeks. Prenat Diagn. 2011;31:135-41.

23. Naylor CD, Sermer M, Chen E, Farine D. Selective screening for gestational diabetes mellitus. N Engl J Med. 1997;337:1591-6.

24. Pintaudi B, Vieste GD, Corrado F, Lucisano G, Pellegrini F, Giunta L, et al. Improvement of selective screening strategy for gestational diabetes through a more accurate definition of high-risk groups. Eur J Endocrinol. 2014:170:87-93.

25. Popova PV, Grineva EN, Gerasimov AS, Kravchuk EN, Ryazantseva EM, Shelepova ES. The new combination of risk factors determining a high risk of gestational diabetes mellitus. Minerva Endocrinol. 2014;40:239-47.

26. Savona-Ventura C, Vassallo J, Marre M, Karamanos BG. A composite risk assessment model to screen for gestational diabetes mellitus among Mediterranean women. Int J Gynaecol Obstet. 2013;120:240-4.

27. Savvidou M, Nelson SM, Makgoba M, Messow CM, Sattar N, Nicolaides K. First-trimester prediction of gestational diabetes mellitus: examining the potential of combining maternal characteristics and laboratory measures. Diabetes. 2010;59:3017-22

28. Shirazian N, Emdadi R, Mahboubi M, Motevallian A, Fazel-Sarjuei Z, Sedighpour N, et al. Screening for gestational diabetes: usefulness of clinical risk factors. Arch Gynecol Obstet. 2009;280:933-7.

29. Syngelaki A, Bredaki FE, Vaikousi E, Maiz N, Nicolaides KH. Body mass index at 11-13 weeks' gestation and pregnancy complications. Fetal Diagn Ther. 2011;30:250-65.

30. Teede HJ, Harrison CL, Teh WT, Paul E, Allan CA. Gestational diabetes: development of an early risk prediction tool to facilitate opportunities for prevention. Aust New Zeal J Obstet Gynaecol. 2011;51:499-504.

31. Tran TS, Hirst JE, Do MA, Morris JM, Jeffery HE. Early prediction of gestational diabetes mellitus in Vietnam: clinical impact of currently recommended diagnostic criteria. Diabetes Care. 2013;36:618-24.

32. Lovati $E$, Beneventi $F$, Simonetta M, Laneri M, Quarleri $L$, Scudeller $L$, et al. Gestational diabetes mellitus: including serum pregnancy-associated plasma protein-A testing in the clinical management of primiparous women? A case-control study. Diabetes Res Clin Pract. 2013;100:340-7.

33. Theriault S, Forest J-C, Masse J, Giguere Y. Validation of early risk-prediction models for gestational diabetes based on clinical characteristics. Diabetes Res Clin Pract. 2014;103:419-25.

34. Van Leeuwen M, Opmeer BC, Zweers EJK, Van Ballegooie E, Ter Brugge HG, De Valk HW, et al. External validation of a clinical scoring system for the risk of gestational diabetes mellitus. Diabetes Res Clin Pract. 2009;85:96-101.

35. Griffin ME, Coffey M, Johnson H, Scanlon P, Foley M, Stronge J, et al. Universal vs. risk factor-based screening for gestational diabetes mellitus: detection rates, gestation at diagnosis and outcome. Diabet Med. 2000;17:26-32.

36. Donders ART, van der Heijden GJMG, Stijnen T, Moons KGM. Review: a gentle introduction to imputation of missing values. J Clin Epidemiol. 2006; 59:1087-91.

37. Sweeting A, Park F, Hyett J. The first trimester: prediction and prevention of the great obstetrical syndromes. Best Pract Res Clin Obstet Gynaecol. 2015;29:183-93.

38. Spencer K, Cowans NJ. The association between gestational diabetes mellitus and first trimester aneuploidy screening markers. Ann Clin Biochem. 2013:50:603-10.

39. Husslein $H$, Lausegger $F$, Leipold $H$, Worda C. Association between pregnancy-associated plasma protein-A and gestational diabetes requiring insulin treatment at 11-14 weeks of gestation. J Matern Neonatal Med. 2012:25:2230-3.

40. Agarwal MM. Gestational diabetes mellitus: an update on the current international diagnostic criteria. World J Diabetes. 2015;6:782-91.

41. Buckley BS, Harreiter J, Damm P, Corcoy R, Chico A, Simmons D, et al. Gestational diabetes mellitus in Europe: prevalence, current screening practice and barriers to screening. A review Diabet Med. 2012;29:844-54

42. Metzger BE, Gabbe SG, Persson B, Buchanan TA, Catalano PA, Damm P, et al. International Association of Diabetes and Pregnancy Study Groups recommendations on the diagnosis and classification of hyperglycemia in pregnancy. Diabetes Care. 2010;33:676-82.

43. Mallett $\mathrm{S}$, Royston $\mathrm{P}$, Dutton $\mathrm{S}$, Waters $\mathrm{R}$, Altman DG. Reporting methods in studies developing prognostic models in cancer: a review. BMC Med. 2010;8:20. 
44. Brunelli VB, Prefumo F. Quality of first trimester risk prediction models for pre-eclampsia: a systematic review. BJOG. 2015;122:904-14.

45. Haskins R, Osmotherly PG, Rivett DA. Validation and impact analysis of prognostic clinical prediction rules for low back pain is needed: a systematic review. J Clin Epidemiol. 2015;68:821-32.

46. Moons KGM, Altman DG, Reitsma JB, loannidis JPA, Macaskill P, Steyerberg EW, et al. Transparent Reporting of a multivariable prediction model for Individual Prognosis Or Diagnosis (TRIPOD): explanation and elaboration. Ann Intern Med. 2015;162:W1.

47. Syngelaki A, Pastides A, Kotecha R, Wright A, Akolekar R, Nicolaides KH. Firsttrimester screening for gestational diabetes mellitus based on maternal characteristics and history. Fetal Diagn Ther. 2014;38:14-21.

48. Sharp AN, Alfirevic Z. First trimester screening can predict adverse pregnancy outcomes. Prenat Diagn. 2014;34:660-7.

49. National Institute for Health and Care Excellence. Diabetes in pregnancy. NICE guideline NG3. http://pathways.nice.org.uk/pathways/diabetes-inpregnancy. Accessed 21 Aug 2015.

50. Bain E, Crane M, Tieu J, Han S, Crowther CA, Middleton P. Diet and exercise interventions for preventing gestational diabetes mellitus. Cochrane Database Syst Rev. 2015;4, CD010443.

51. Weston AD, Hood L. Systems biology, proteomics, and the future of health care: toward predictive, preventative, and personalized medicine. J Proteome Res. 2004;3:179-96.

\section{Submit your next manuscript to BioMed Central} and we will help you at every step:

- We accept pre-submission inquiries

- Our selector tool helps you to find the most relevant journal

- We provide round the clock customer support

- Convenient online submission

- Thorough peer review

- Inclusion in PubMed and all major indexing services

- Maximum visibility for your research

Submit your manuscript at www.biomedcentral.com/submit
Biomed Central 